Vol.02/ No. 02

Pages: $100-107$

https://www.irojournals.com/itdw/

DOI: https://doi.org/10.36548/jitdw.2020.2.003

\title{
Geospatial and Social Media Analytics for Emotion Analysis of Theme Park Visitors using Text Mining and GIS
}

\author{
Dr. Samuel Manoharan, \\ Professor, \\ Department of Electronics, \\ Bharathiyar College of Engineering and Technology, \\ India. \\ Email: jsamuel@bcetedu.in \\ Prof. Sathish, \\ Department of EEE, \\ Eritrea Institute of Technology, \\ Eritrea. \\ Email: sathesh4you@gmail.com
}

\begin{abstract}
Scrutinizing the emotions of customers and social media analytics are gaining popularity in the recent days. However, analysis of the emotions of visitors in theme parks are done on a lesser scale. In this paper, based on social media messages, the emotions of the visitors of a theme park is analyzed using geospatial as well as social media analytics convergence and visualization of cohesive places where expressions are gathered. Based on the Russell's Circumplex Model of Affect, the words and emotions are analyzed in around 50,000 tweets collected of which 20,400 tweets contained one or more such words. Analysis of exploratory spatial data based on GIS and analysis of text mining represents various emotion in each quadrant based on the tweets. The visitor emotions are associated to various topics and emotions of considerable spatial variations. Based on the significant clustering of emotions in each quadrant, the areas of riding attraction in the theme park are identified and displayed using this research approach. Based on the analysis and implications of this research work, it is possible to develop ways in which the pleasant emotions of the visitors can be evoked by practitioners.
\end{abstract}

Keywords: Theme Park; Twitter; Social media analytics; Geospatial analytics; Customer emotion;

\section{Introduction}

The cognitive behavioural system is greatly impacted by emotions based on several prior studies on social media analytics [1]. Exploring the emotional outcomes and states and other relevant factors by practitioners and researchers by analysing the on-site emotions of the visitors and emotional experiences like relaxation and excitement is essential in places of tourist attractions [2]. Beverages, food, customer service, events, landscape, cast staff, contents, rides and various such components are staged in a theme park. They have a large contribution towards economy of the country in terms of tourism and travel as it attracts several travellers to particular destinations on a regular basis. Based on several researches, it 
Journal of Information Technology and Digital World (2020)

Vol.02/ No. 02

Pages: $100-107$

https://www.irojournals.com/itdw/

DOI: https://doi.org/10.36548/jitdw.2020.2.003

has been observed that the success of this industry is greatly influenced by the emotional experiences of the visitors of the theme park [3].

For enhancing the experience of visitors and motivating more people to visit the theme park, excitement, delight and such pleasant emotions are examined by several scholars in the tourism industry [4]. The emotional needs of the visitors are fulfilled and exciting experiences are delivered to them by designing programs and attractions based on the understanding of the emotions of the visitors [5]. In order to offer memorable moments and exciting experiences to the customers, a service stage is created based on the recommended behaviour, loyalty, customer satisfaction and by enhancing the customer experiences based on the suggestive recommendations of the previous literatures [6].

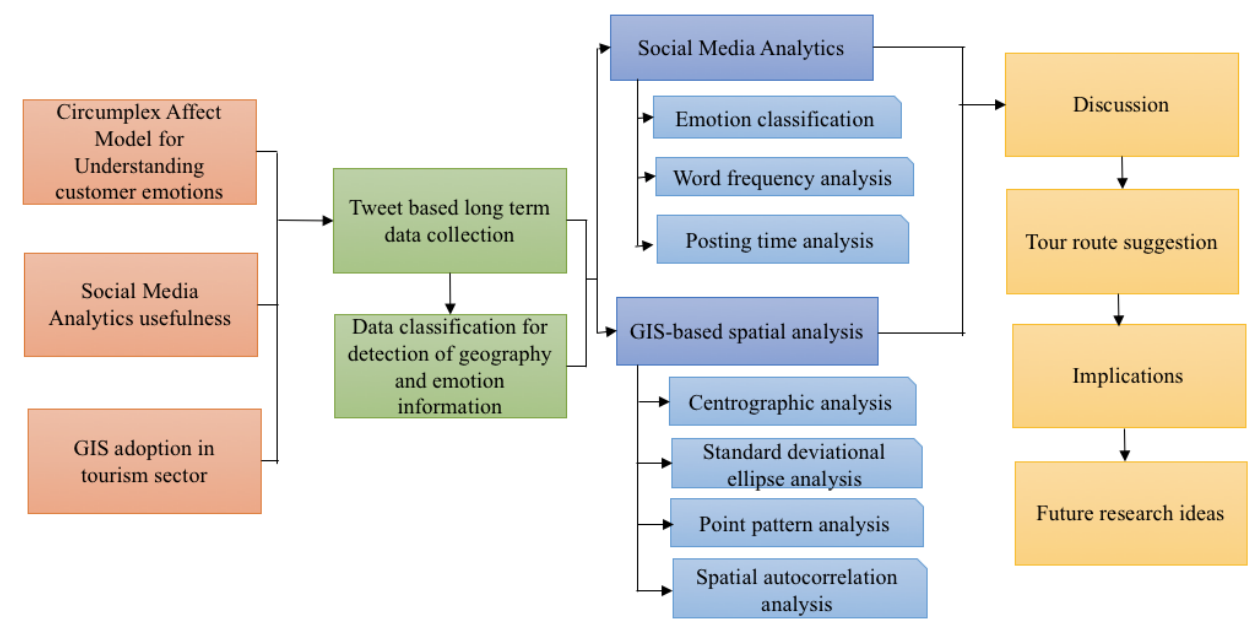

(a)

(b)

(c)

(d)

Figure 1: Research Framework

The travel industry has several challenges in remaining successful. Estimation of the emotional state of the customer has contributed greatly towards the success of this industry despite several challenges. With the passing of time, the experiences and emotions of the customers in the theme park can be distorted easily [7]. Reconstruction of the original emotion can be performed if it is mingled with other emotions after the experience using the interface. False memories and misleading information can be created if the genuine emotions of the visitors are not measured and returned. The past and distorted memories can be recalled by the visitors based on false memory paradigm. The real time experiences of travelers are measured accurately by various approaches and research tools. The travel experiences and measurement of on-site emotions of travelers is done in previous research works [8]. 
Journal of Information Technology and Digital World (2020)

Vol.02/ No. 02

Pages: $100-107$

https://www.irojournals.com/itdw/

DOI: https://doi.org/10.36548/jitdw.2020.2.003

\section{Related Works}

At various tourism destinations and places of interest, unique experiences are sought after by travellers which is an ultimate offering in tourism [9-11]. In tourism, the formation of memory is affected by meaningful experiences and perceptions of customers due to the major factor which is emotions of the tourists. In order to differentiate the tourism destination from its competitors, creating and delivering memorable experiences to the customers is one of the most suited competitive advantage. Customer satisfaction is affected greatly by the emotions of the customer along with happiness, pleasure and positive emotions [12]. For efficient management of traveller experience, an important indicator is the emotions of the customers.

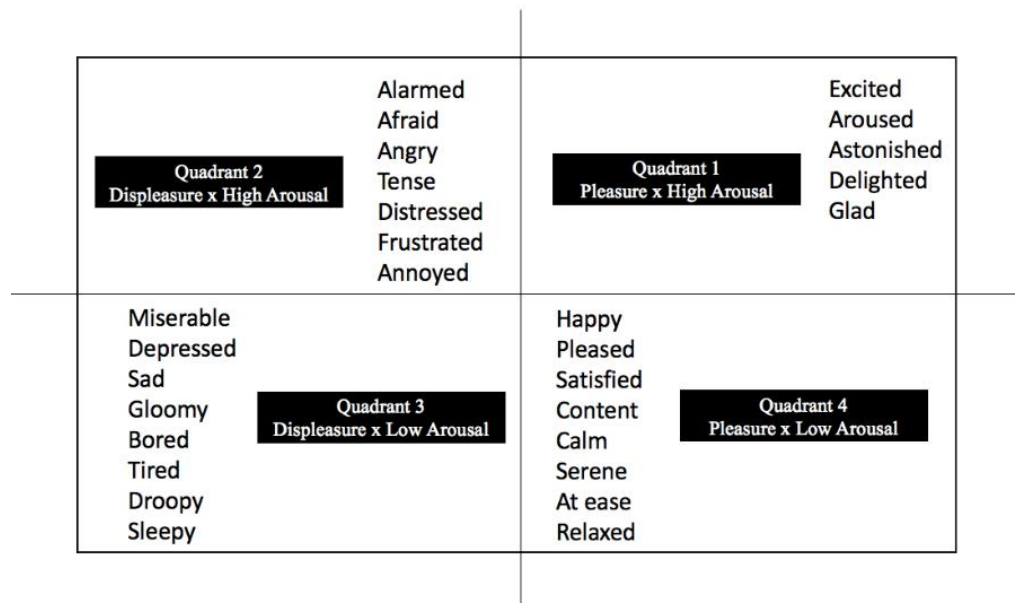

Figure 2: Circumplex model of Affect for emotional words classification

Emotional appeals of the users are driven largely by theme park experiences based on the services and products relating to sensational experiences of the visitors in popular entertainment venues and travel destinations of the tourism industries [13]. The visitors of the theme park are satisfied if the human interaction and environmental factors of the park satisfies the expectations of the visitor. The emotional activation as well as exceeding the expectations of the customers in a positive manner play a major role in affecting the customer experience state beyond the cognitive evaluation. Expression of positive emotional states by the customers such as excitement, joy, delight, and so on improves the future positive behavior and satisfaction of the customers [14]. Sensorial experiences like touch, taste, smell, sound and sight are created with the programs and equipment of higher end in the recent theme parks. The interaction of visitors with other visitors and staffs, and the physical factors are some of the elements that affect the satisfaction level and have significant influence on the experience and emotional aspect of the visitors of the theme park. In order to enhance the marketing performance of the theme park, it is essential to evaluate the experience of the visitors and monitor their emotional state on-site since these factors determine the emotions of the visitors [15]. 
Journal of Information Technology and Digital World (2020)

Vol.02/ No. 02

Pages: $100-107$

https://www.irojournals.com/itdw/

DOI: https://doi.org/10.36548/jitdw.2020.2.003

\section{Proposed Work}

\subsection{Collection of Information and screening}

A template of Google Sheet is used for embedding the application using TAGS v6 for collection and analysis of information. Factors such as geographic coordinates, time after publication, sender accounts, tweet messages, hashtags, words and several such conditions and options are analyzed using the tool for identifying the target tweets. These tweets sent from a theme park are gathered irrespective of any other considerations. The geographical area of the theme park is measured and the circle perimeter is set with the help of Google Maps. The geocode query is set with TAGS V6 for collection of data between a specific set of dates for real time analysis purpose.

\subsection{Tweet Classification by emotional words}

Microsoft Excel sheet is used for filtering the tweets based on Circumplex model if it contains any emotional words. Based on this analysis, it was identified that 20,400 out of the 50,000 tweets contained at least one of the 28 emotional words from the circumplex model. Further, spatial analysis and text mining is performed on these tweets for classification of the emotional words into one of the four quadrants of the model.

\subsection{Spatial Analysis based on GIS}

In large tourist destinations, aggregation of the emotion of the visitors is critical for defining the optimal analysis unit during exploration of the four emotion quadrants of spatial patterns. Based on a prior analysis pattern, we employ a cell of the dimensions $10 \times 10$ meters for this study. Over a thousand cells were included in the study area due to this calculation. ArcGIS and the extension tool of Spatial Statistics is used for conducting analysis of data with six steps. The point shape file format of GIS is used for storing the refined contents of the tweets. The spatial information layer or geographical theme representation can be stored in the digital format using the shape files of GIS.

As represented in Figure 2, two orthogonal axes are used to differentiate the types of emotions and the expression of 28 terms corresponding to the arousal according to the circumplex model. Several scholars have discussed and analyzed the service management in marketing by studying the emotions of the customer by using the Circumplex Model. The differences and similarities between the emotions are described by this model in a simple and intuitive way. 
Journal of Information Technology and Digital World (2020)

Vol.02/ No. 02

Pages: $100-107$

https://www.irojournals.com/itdw/

DOI: https://doi.org/10.36548/jitdw.2020.2.003

\section{Results and Discussion}

The tweets are analyzed and based on the four-quadrant datasets, the emotional words in the tweets are counted. Based on the frequency of the words, the emotional domains are categorized and clarified. Common terms like happy and sad are excluded in the circumplex model. The results show that the most dominant words in the dataset are derived from the quadrant 1 when compared to all the other quadrants.
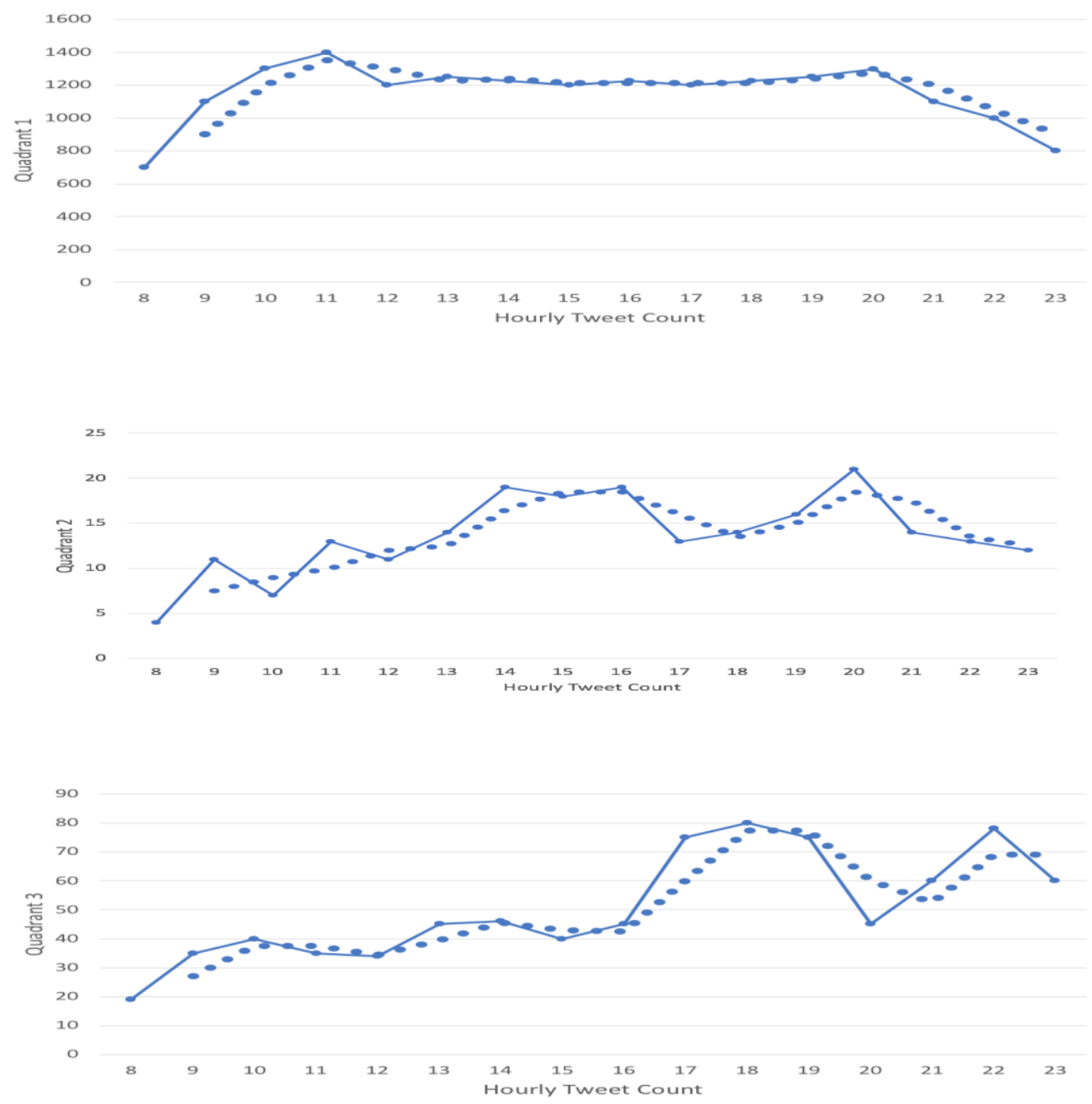
Journal of Information Technology and Digital World (2020)

Vol.02/ No. 02

Pages: $100-107$

https://www.irojournals.com/itdw/

DOI: https://doi.org/10.36548/jitdw.2020.2.003

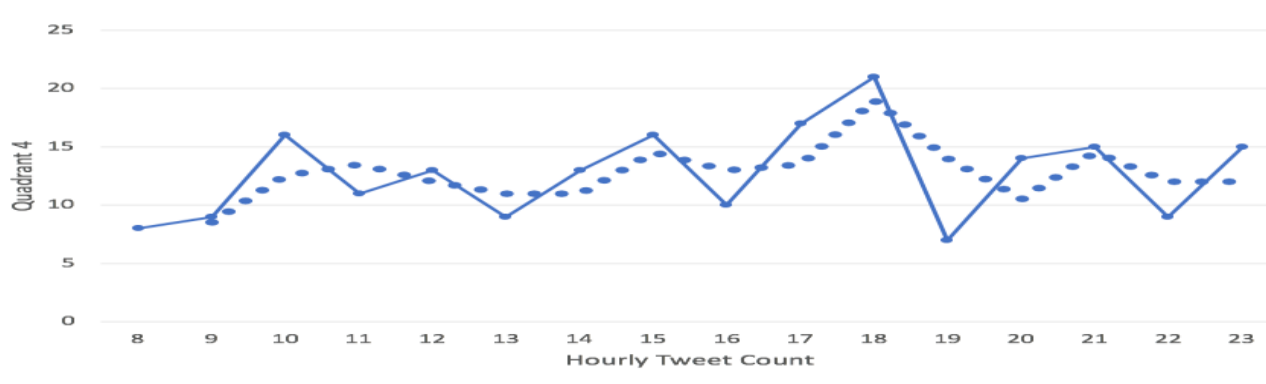

Figure 3: Hourly tweet count based on four emotion quadrants

Figure 3 represents four graphs that represents the emotional tweet count and their patterns based on the time of publication of every individual tweet. There is a gradual increase in the tweet count in quadrant 1 between $11 \mathrm{am}$ to $7 \mathrm{pm}$ and there is a dip after the specified time duration. There is an overall fluctuation in the tweet count of quadrant 2 and 3 which is represented as a growing pattern in the graph. Between 5 to $7 \mathrm{pm}$, the number of tweets published in the third quadrant is more. Similarly, the tweets in fourth quadrant increases steadily at around $10 \mathrm{pm}$. The different types of visitors in the theme park are analyzed and studied based on the information obtained from the twitter text data. The location data is also gathered to examine the emotions evoked based on the spatial distributions. The four types of emotions corresponding to the 28 words represented by the circumplex affect model are studied, differentiated and analyzed by visualizing the hotspots of attraction in the theme park. The emotional patterns are analyzed on hourly basis and based on the emotional quadrant and provides insightful information using social media analytics. Some of the words used for representing pleasurable and high arousal experience in Q1 includes anniversary, time, adventure, birthday and so on. In Q2, the displeasure and high-arousal emotion words like hangry, person, lol, people and mad were included in the tweets. In Q3, people, end, work, lol, night, time and such words were included representing displeasure and low-arousal emotions. Time, nice, main, care and such words representing pleasurable and low-arousal experiences are found in Q4 level tweets. Based on the GIS, the hot spots in the theme park is identified for each quadrant. The joyful, pleasant and exiting experiences are recreated and the areas which fallback are monitored and altered to meet the requirements of the customers.

\section{Conclusion}

Several millions of travelers are attracted by theme parks every year. They also generate hefty amounts in terms of tourism for the society and operate as landmarks. These theme parks are nicknamed by the general public as the happiest place on earth. These tourism destinations evoke positive and pleasant emotions of the visitors and travelers. The emotional experiences of the customers are not examined comprehensively in most of the research papers related to theme parks and other tourist attractions. The memorable and enjoyable experiences of travelers should be improved by monitoring the consumption experiences and emotions of the customers according to previous studies. The service management of theme park are provided with suggestions for delivering a series of processes that can be developed based on the research theory. Several rich research methodologies are also combined in 
Journal of Information Technology and Digital World (2020)

Vol.02/ No. 02

Pages: $100-107$

https://www.irojournals.com/itdw/

DOI: https://doi.org/10.36548/jitdw.2020.2.003

this work offering several possibilities and benefits. The positive and negative emotions of the visitors are measured by detecting the four-quadrant emotions using the Circumplex Affect Model. 20,400 tweets out of 50,000 containing the emotion words are analyzed and examined. In comparison with the existing techniques such as SentiStrength, the proposed technique improves the emotion measurement and analysis quality. Several practical implications and sophisticated spatial analysis can be employed for the management of the theme park based on this study. The theoretical background can be used for the expansion of the emotional word spectrum for further research. Two significant research approaches are combined in a unique fashion in this work and the emotional moods are scrutinized in one theme park. Large festivals, travel destinations and other cases can be investigated to explore the possibilities and opportunities of this research work.

\section{References}

[1] Kim, H. J., Chae, B. K., \& Park, S. B. (2018). Exploring public space through social media: an exploratory case study on the High Line New York City. Urban Design International, 23(2), 69-85.

[2] Mirzaalian, F., \& Halpenny, E. (2019). Social media analytics in hospitality and tourism. Journal of Hospitality and Tourism Technology.

[3] Lupu, C., \& Stoleriu, O. M. (2019, March). A spatial and sentiment analysis of tourism related tweets in Romania. In ISCONTOUR 2019 Tourism Research Perspectives: Proceedings of the International Student Conference in Tourism Research (Vol. 7, p. 149). BoD-Books on Demand.

[4] Gupta, N. (2018). Exploring Happiness Indicators In Cities and Industrial Sectors Using Twitter and Urban GIS Data (Doctoral dissertation, University of Warwick).

[5] Kang, Y., Jia, Q., Gao, S., Zeng, X., Wang, Y., Angsuesser, S., ... \& Fei, T. (2019). Extracting human emotions at different places based on facial expressions and spatial clustering analysis. Transactions in GIS, 23(3), 450-480.

[6] Zhang, X., \& Mu, L. (2020). Incorporating Online Survey and Social Media Data into a GIS Analysis for Measuring Walkability. In Geospatial Technologies for Urban Health (pp. 133155). Springer, Cham.

[7] Wang, F., Peng, X., Qin, Y., \& Wang, C. (2020). What can the news tell us about the environmental performance of tourist areas? A text mining approach to China's National 5A Tourist Areas. Sustainable Cities and Society, 52, 101818.

[8] Miah, S. J., Vu, H. Q., Gammack, J., \& McGrath, M. (2017). A big data analytics method for tourist behaviour analysis. Information \& Management, 54(6), 771-785.

[9] Toivonen, T., Heikinheimo, V., Fink, C., Hausmann, A., Hiippala, T., Järv, O., ... \& Di Minin, E. (2019). Social media data for conservation science: A methodological overview. Biological Conservation, 233, 298-315.

[10] Bruno, S., Yang, C., Tian, W., Xie, Z., \& Shao, Y. (2019). Exploring the characteristics of tourism industry by analyzing consumer review contents from social media: a case study of Bamako, Mali. Geo-spatial Information Science, 22(3), 214-222. 
Journal of Information Technology and Digital World (2020)

Vol.02/ No. 02

Pages: $100-107$

https://www.irojournals.com/itdw/

DOI: https://doi.org/10.36548/jitdw.2020.2.003

[11] Ullah, H., Wan, W., Ali Haidery, S., Khan, N. U., Ebrahimpour, Z., \& Luo, T. (2019). Analyzing the Spatiotemporal Patterns in Green Spaces for Urban Studies Using LocationBased Social Media Data. ISPRS International Journal of Geo-Information, 8(11), 506.

[12] Ristea, A., Al Boni, M., Resch, B., Gerber, M. S., \& Leitner, M. (2020). Spatial crime distribution and prediction for sporting events using social media. International Journal of Geographical Information Science, 1-32.

[13] da Mota, V. T., \& Pickering, C. (2020). Using social media to assess nature-based tourism: Current research and future trends. Journal of Outdoor Recreation and Tourism, 30, 100295.

[14] Ghermandi, A., \& Sinclair, M. (2019). Passive crowdsourcing of social media in environmental research: A systematic map. Global environmental change, 55, 36-47.

[15] Sathesh, A. (2019). ENHANCED SOFT COMPUTING APPROACHES FOR INTRUSION DETECTION SCHEMES IN SOCIAL MEDIA NETWORKS. Journal of Soft Computing Paradigm (JSCP), 1(02), 69-79.

\section{Authors Biography}

Dr. Samuel Manoharan, works as Professor, in Department of Electronics, in Bharathiyar College of Engineering and Technology, India, his are of research are Artificial Intelligence, Decision Making, Medical Informatics, Decision Support Systems, Fuzzy Algorithms and Theories, Information Retrieval Systems, Internet-of-Things, Cloud Computing, Computer Networks, Wireless Technologies, Big Data and E-applications in Social, health, and Government sectors

Prof .Sathish works in the Department of EEE,in Eritrea Institute of Technology,Eritrea. His interested area of research includes modern computer Science and emerging smart technologies in various aspects of Wireless Communications, Cloud Computing, Computer System Engineering, Communication Technologies, Information Processing, Computer Networks, Web Technologies, Computing \& Communications, Automation, Image processing and Wireless Communications. 